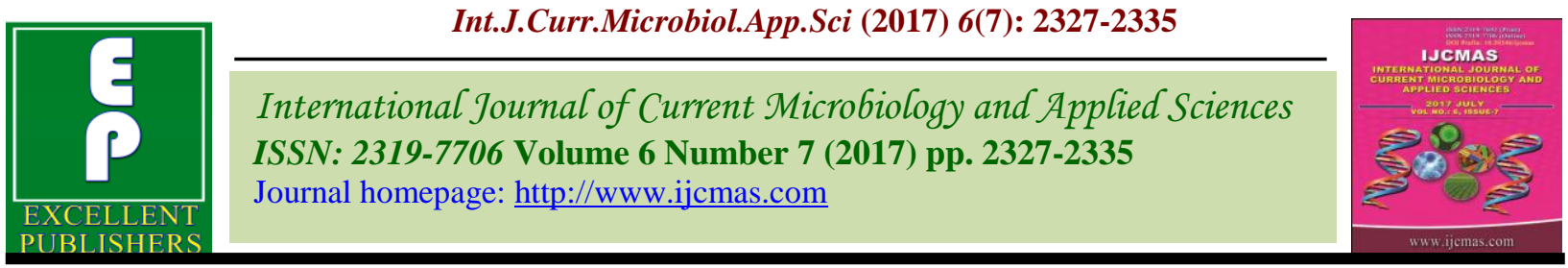

Original Research Article https://doi.org/10.20546/ijcmas.2017.607.275

\title{
Rice Acreage Estimation in Thanjavur, Tamil Nadu Using Lands at 8 OLIIMAGES and GIS Techniques
}

\author{
K. Ajith ${ }^{\text {* }}$, V. Geethalakshmi ${ }^{2}$, K.P. Ragunath ${ }^{3}$, S. Pazhanivelan ${ }^{3}$ and S. Panneerselvam ${ }^{1}$ \\ ${ }^{1}$ Agro Climate Research Centre, TNAU, Coimbatore, Tamil Nadu, India \\ ${ }^{2}$ Department of Agronomy, AC \& RI, Madurai, Tamil Nadu, India \\ ${ }^{3}$ Department of Remote Sensing \& GIS, TNAU, Coimbatore, Tamil Nadu, India \\ *Corresponding author
}

\begin{abstract}
A B S T R A C T
Rice acreage estimation prior to harvest is very essential in predicting agricultural production for devising policies to face contingencies. The present study emphasizes

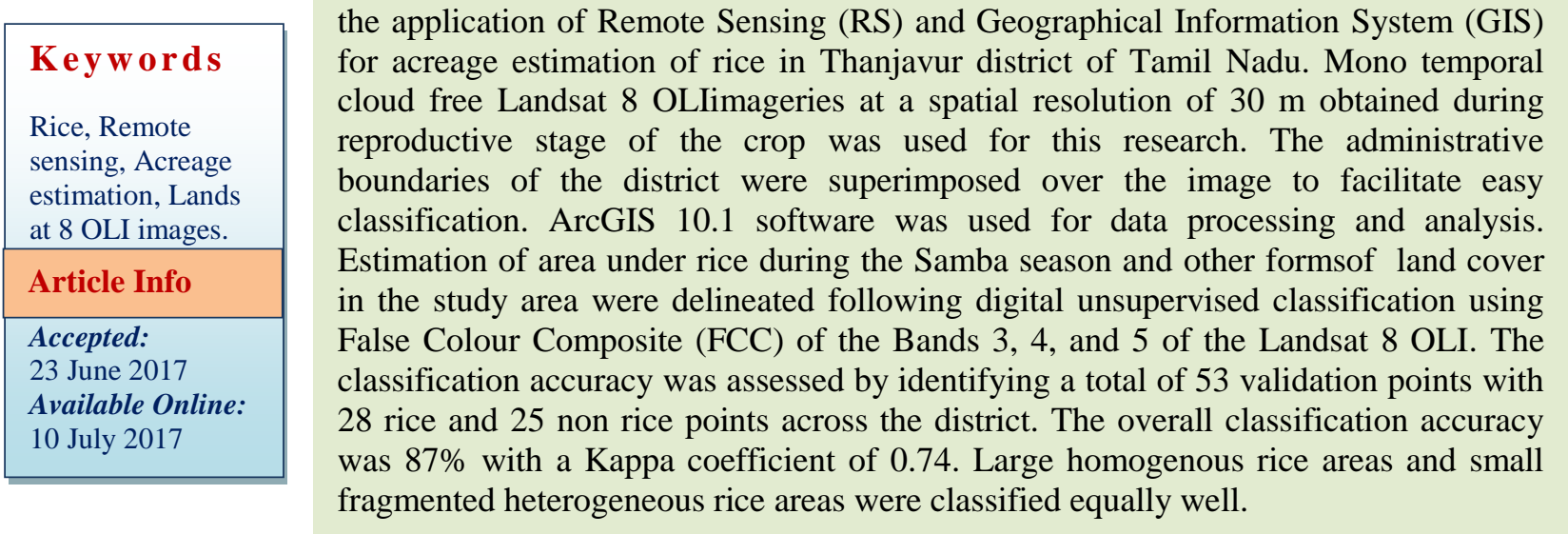

\section{Introduction}

Rice (Oryza sativa L.) is one of the most important food crops in the world occupying about 140 million hectares, feeding more than $50 \%$ of the world's population (Khush, 2005). Asia accounts for $90 \%$ of the world's rice production and consumption because of its favourable hot and humid climate. Rice crop grows between $55^{\circ} \mathrm{N}$ and $36^{\circ} \mathrm{S}$ latitudes under diverse conditions like flooded, irrigated and rain fed ecosystems. India contributed 21 per cent (155.4 million tonnes) of world's rice production (738.2 million tonnes) during
2015 (FAO, 2016). Tamil Nadu has produced 79.14 lakh tonnes of rice from an area of 18.3 lakh hectares in 2014-15 (Vaithilingam, 2015). Timely and accurate estimation of rice areas and forecasting its production can provide vital information for governments, planners, and decision makers in formulating policies with respect to import/ export in the event of shortfall or surplus (Mostafa, 2015). Rice mapping during 1980 s to early 1990 s was mainly based on agricultural statistical data updated on regular time-intervals (Huke 
and Huke, 1997). More recently, remote sensing has been widely used in large scale crop acreage estimation because it has wide swath and can provide effective and timely spatial and temporal information on crop growth conditions (Yang, 2007; Chen, 2007; Okamoto and Kawashima, 1999; Koppe et al., 2013).

Remote sensing-based methods have already been proven as an effective alternative for mapping rice area (Tennakoon et al., 1992; Yang et al., 2008). The benefits of remote sensing technology include: (i) spatial coverage over a large geographic area (ii) availability during all seasons (iii) relatively low cost, since some optical images are freely available (i.e., MODIS, Landsat); although radar data are usually a bit costly (e.g., CAD $\$ 4000$ per scene); (iv) efficient analysis (v) they provide information in a timely manner and (vi) they are capable of delineating detailed spatial distributions of areas under rice cultivation (Mosleh et al., 2015). Satellite data have been used in rice mapping, either as mono-temporal or multitemporal inputs. Using mono temporal image data has potential of detecting rice fields, as acquisition of cloud free image is often difficult during rice growing period. Many researchers have done commendable works in this area. Karydas et al., (2015), developed a rule-based algorithm for rice cultivation mapping using Landsat 8 time series for the plains of Thessaloniki, Greece. Genc et al., (2014), in an attempt to determine the paddy field, generated land use land cover maps of Biga town using Landsat data in six classes. Yedage et al., (2013), dealt with the identification and assessment of pomegranate cultivation area in Maharastra using IRS P6 and LANDSAT-7 data. Goswami et al., (2012), used single dates, cloud free Resources at -1 LISS- III digital data coinciding with flowering stage of wheat crop for acreage estimation. Shao et al., (2001), examined the backscatter behavior of rice as a function of time using multi temporal RADARSAT data acquired in 1996 and 1997. A rice-type distribution map was produced, showing four types of rice with different life spans ranging from 80 days to $120 \pm 5$ days. The objective of this research was to assess the prospective of mapping rice cultivation areas using medium-to- high resolution optical satellite data, taking advantage of open source Landsat 8 OLI (Operational Land Imager) time series, provided by the United States Geological Survey (USGS). The basic hypothesis of the research was that Landsat 8 time series have the potential to depict rice crop with very high accuracy.

\section{Materials and Methods}

\section{Study area}

The Thanjavur district of Tamil Nadu in India that extends over an area of 3,39,657 ha was taken for the study (Fig. 1). Thanjavur is located between $10^{0} 8^{\prime}$ to $11^{0} 12^{\prime}$ North latitudes and $78^{\circ} 48^{\prime}$ to $79^{\circ} 38^{\prime}$ East longitudes in Central Tamil Nadu bounded on the northeast by Nagapattinam District, on the east by Tiruvarur District, on the south by the Bay of Bengal on the west by Pudukkottai District, and on the north by the river Kollidam, across which lie Tiruchirappalli and Perambalur districts. Thanjavur was selected for the study because it is considered as the rice bowl of Tamil Nadu. It is one of the major districts of the Cauvery Delta region which is referred as the "Granary of South India" due to the high fertility and share of food grains to the state. The mean annual rainfall of the Thanjavur is $938 \mathrm{~mm}$. The South-West monsoon sets in during $2^{\text {nd }}$ week of June and continues till $4^{\text {th }}$ week of September followed by North-East monsoon. The rainfall during South-West monsoon (329 $\mathrm{mm}$ ) period is much lower than that of NorthEast monsoon (462 $\mathrm{mm}$ ) which sets in during 
$3^{\text {rd }}$ week of October and continues till the $4^{\text {th }}$ week of December and winter period starts in January. Kuruvai (May- June to August), Samba (Aug to Jan - Feb) and Thaladi (SepOct to Feb- Mar) are the major rice growing seasons in the district. The study was conducted during 2015-16 Samba rice season, which is the major rice-growing period in the district. During this period medium to long duration varieties of rice are preferred.

\section{Remote Sensing Data}

Landsat 8 OLI, Level $1 \mathrm{~T}$ product at a spatial resolution of $30 \mathrm{~m}$ was used for this research. Three cloud free $(<5 \%)$ GeoTIFF images in two paths and two rows were downloaded from https://glovis.usgs.govas the whole area of Thanjavur district is covered by three scenes (Table 1). The raw satellite imagery obtained is presented in figure 2. The administrative boundary of the study area is overlaid on the image to extract the entire pixel belonging to study district.

\section{Creating a composite from Landat 8 OLI imagery}

Landsat 8 OLI images were acquired in grayscale and a different image was downloaded for each one of the bands. By creating a composite image of different bands, the images could be displayed in colour. Displaying bands in the RGB format allows us to see different features within a scene and helps to become more familiar with the features i.e. to identify urban areas, forests, agriculture, and water bodies. Familiarity with Landsat scene is important in order to carry out different types of analyses, such as unsupervised classifications, supervised classifications etc. Landsat 8 OLI and Thermal Infrared Sensor (TIRS) images consist of nine spectral bands (Table 2). The approximate scene size is $170 \mathrm{~km}$ north-south by $183 \mathrm{~km}$ east-west. Using ArcGIS 10.1, a new composite image was made by combining Band 3 (Green), Band 4(Red) and Band 5(Near Infrared) in False Colour Composite (FCC). The three adjacent composite raster datasets were mosaicked together for obtaining a complete coverage of Thanjavur district (Fig. 3). Mosaiking enabled to combine three raster datasets into a single, seamless raster image which facilitates easy classification.

\section{Isocluster classification and rice area estimation}

Isocluster unsupervised classification is a method of identifying, grouping, and labeling features in an image according to their spectral values. In unsupervised classification, pixels are clustered together based on spectral homogeneity and spectral distance. The mosaicked composite image was classified and the rice area was delineated by identification and removal of classes like water bodies, riverbeds, coconut plantations and settlements. Land use mask available in the Department of Remote Sensing and GIS was used for masking the above classes. An isocluster classification method which consisting of six classes was found suitable for the study.

\section{Results and Discussion}

\section{Rice area estimation}

Rice area maps were generated from mono temporal Landsat8 OLI imageries for all the 14 blocks of Thanjavur district and the classified image is presented in figure 4 . The total area estimated for the whole district during Samba season (2015-16) was 1,09,799 ha. The paddy rice planting area is estimated to be approximately $32 \%$ of the study area. Thanjavur block recorded the maximum rice area $(15.93 \%)$ among the 14 blocks in the district followed by Orathanadu block (14.05 
$\%)$. The least rice area was obtained from Peravurani block (5.25\%) (Fig. 5). The validation of rice acreage estimation was done by classifying the whole study area into rice and non rice areas. All the remaining classes except rice were grouped into a single non rice class for assessment of accuracy. A total of 53 validation points were identified with 28 rice and 25 non rice points from various parts of the district (Fig. 6). During Samba rice season (2015-16) ground data was collected from these points using Global Positioning System (GPS) as well as camera. Generally the areas have a homogenous land cover in a $15-\mathrm{m}$ radius around the GPS points were selected. The ground truth data was collected from the field with in the season i.e. during the flowering stage or before harvest of the crop. The accuracy assessment is a comparison of the classified rice areas against the ground truth data. Confusion matrix and kappa coefficient were developed based on the rice areas and non-rice areas by comparing predicted and actual land covers in order to obtain the accuracy. A summary of the validation data, rice areas, non rice areas and accuracy of classification is presented in table 3. The overall classification accuracy was $87 \%$ with a Kappa coefficient of 0.74 . Large homogenous rice areas and small fragmented heterogeneous rice areas were classified equally well.

Usually the Kuruvai coincides with the SouthWest monsoon season and Samba with the North-East monsoon season. Since the percentage contribution of North-East monsoon is more compared to South-West monsoon, cloud interference will be more during Samba season than Kuruvaior Thaladi. So the availability of cloud free images will be more during Kuruvai/Thaladi. But generally it will be difficult to obtain cloud free or high quality optical images during the early period of Samba season. Hence the cloud free optical images coinciding with the reproductive stage of Samba crop were utilized and the accuracy was fairly good. From this study it can be inferred that rice area cultivation extent of Samba season with high precision can be derived by using mono temporal freely available medium to high resolution optical data during December / January. Further, monitoring crop proportion using Landsat 8 OLI and iso-cluster classification provided an effective and easy method to maintain the monitoring accuracy. Rice crop acreage estimation during Kuruvai and Thaladi season also can be obtained by utilizing cloud free mono temporal images available during respective period.

Crop identification and discrimination using optical remote sensed data is based on the fact each crop has unique spectral signature. Typical spectral reflectance of a crop shows absorption due to pigment in visible region $(0.62-0.68 \mu \mathrm{m})$.

High reflectance is shown in the near infrared region $(0.7$ to $1 \mu \mathrm{m})$ is because of internal cellular structure of the leaves and vigour of crop is manifested by ratio of absorption in red and the reflectance in the near infrared region (Dadhwaland Ray, 2000). Identification and delineation of existing crops during the Samba season of rice, other agriculture forms and other land cover in the study area were carried out following digital unsupervised classification using FCC of the Band 3, 4, and 5 of the Landsat 8 OLI.

Acreage estimation of rice using optical satellite images often face challenges primarily due to the interception of clouds. Hence acreage estimation with mono temporal images has of great value. Mono temporal Landsat 8 OLI images with minimum cloud amount were used for the study. 
Table.1 Landsat 8 OLI data acquisition schedule

\begin{tabular}{|c|c|c|c|}
\hline \multicolumn{4}{|c|}{ Landsat 8 OLI data acquisition } \\
\hline Date & Path & Row & Product \\
\hline $18 / 01 / 16$ & 142 & 52 & LC81420522016018LGN00 \\
\hline $18 / 01 / 16$ & 142 & 53 & LC81420532016018LGN00 \\
\hline $10 / 02 / 16$ & 143 & 52 & LC81430522016041LGN00 \\
\hline
\end{tabular}

Table.2 Band designation for Landsat 8 OLI and TIRS

\begin{tabular}{|c|c|c|c|}
\hline \multirow{12}{*}{$\begin{array}{l}\text { Landsat } 8 \\
\text { Operational } \\
\text { Land } \\
\text { Imager } \\
\text { (OLI) } \\
\text { and } \\
\text { Thermal } \\
\text { Infrared } \\
\text { Sensor } \\
\text { (TIRS) }\end{array}$} & Bands & $\begin{array}{l}\text { Wavelength } \\
\text { (micrometers) }\end{array}$ & $\begin{array}{l}\begin{array}{l}\text { Resolution } \\
\text { (meters) }\end{array} \\
\text { (m) }\end{array}$ \\
\hline & Band 1 - Ultra Blue (coastal/aerosol) & $0.43-0.45$ & 30 \\
\hline & Band 2 - Blue & $0.45-0.51$ & 30 \\
\hline & Band 3 - Green & $0.53-0.59$ & 30 \\
\hline & Band 4 - Red & $0.64-0.67$ & 30 \\
\hline & Band 5 - Near Infrared (NIR) & $0.85-0.88$ & 30 \\
\hline & $\begin{array}{l}\text { Band } 6 \text { - Shortwave Infrared } \\
\text { (SWIR) } 1\end{array}$ & $1.57-1.65$ & 30 \\
\hline & $\begin{array}{l}\text { Band } 7 \text { - Shortwave Infrared } \\
\text { (SWIR) } 2\end{array}$ & $2.11-2.29$ & 30 \\
\hline & Band 8 - Panchromatic & $0.50-0.68$ & 15 \\
\hline & Band 9 - Cirrus & $1.36-1.38$ & 30 \\
\hline & $\begin{array}{l}\text { Band } 10 \text { - Thermal Infrared (TIRS) } \\
1\end{array}$ & $10.60-11.19$ & $100 *(30)$ \\
\hline & $\begin{array}{l}\text { Band } 11 \text { - Thermal Infrared (TIRS) } \\
2\end{array}$ & $11.50-12.51$ & $100 *(30)$ \\
\hline
\end{tabular}

* TIRS bands are acquired at 100 meter resolution, but are resampled to 30 meter in delivered data product

Table. 3 Confusion matrix for accuracy assessment of rice classification

\begin{tabular}{|l|l|l|l|l|}
\hline & \multicolumn{5}{|c|}{ Predicted class from the map } \\
\hline & Class & Rice & Non-rice & Accuracy \\
\hline & Rice & 24 & 4 & $86 \%$ \\
\hline & Non- Rice & 3 & 22 & $88 \%$ \\
\hline & Reliability & $89 \%$ & $85 \%$ & $87 \%$ \\
\hline \multicolumn{2}{|l|}{ Average accuracy } & $87 \%$ & & \\
\hline Average reliability & $87 \%$ & & \\
\hline Kappa coefficient & 0.86 & & \\
\hline
\end{tabular}


Fig.1 Location map of Thanjavur district

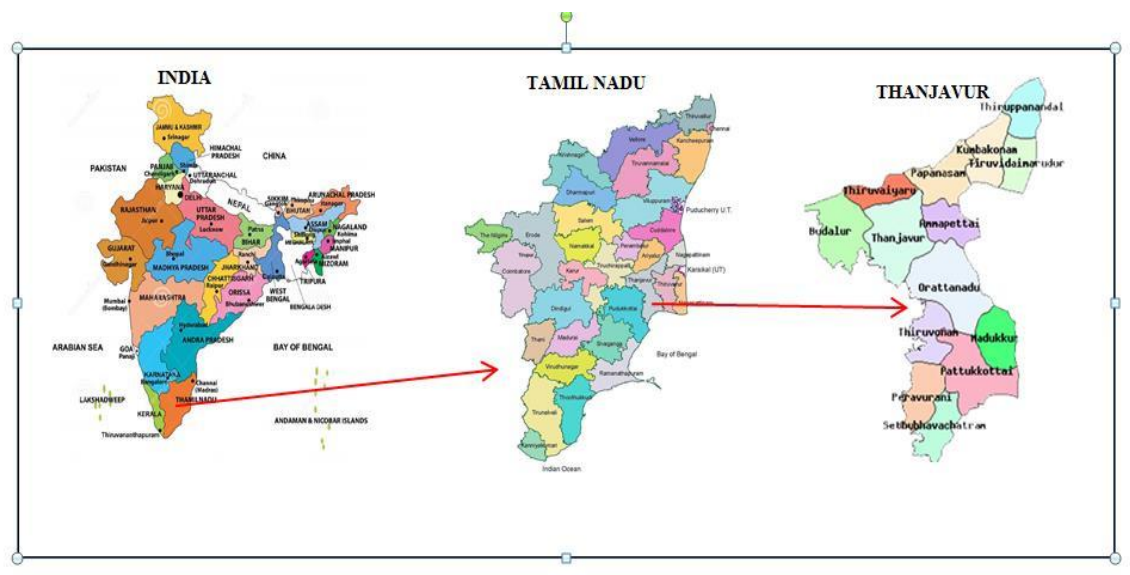

Fig.2 Raw satellite imagery

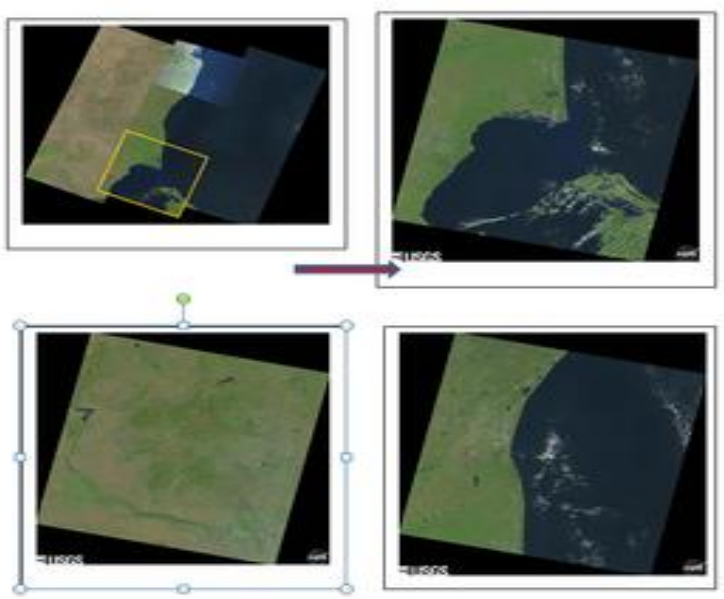

Fig.3 Mosaiked composite image of Thanjavur

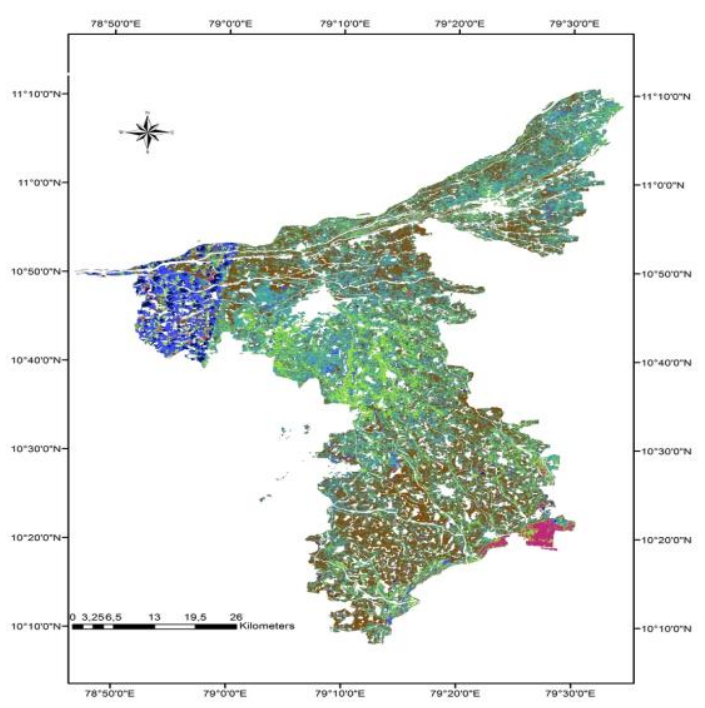


Fig.4 Rice area map of Thanjavur

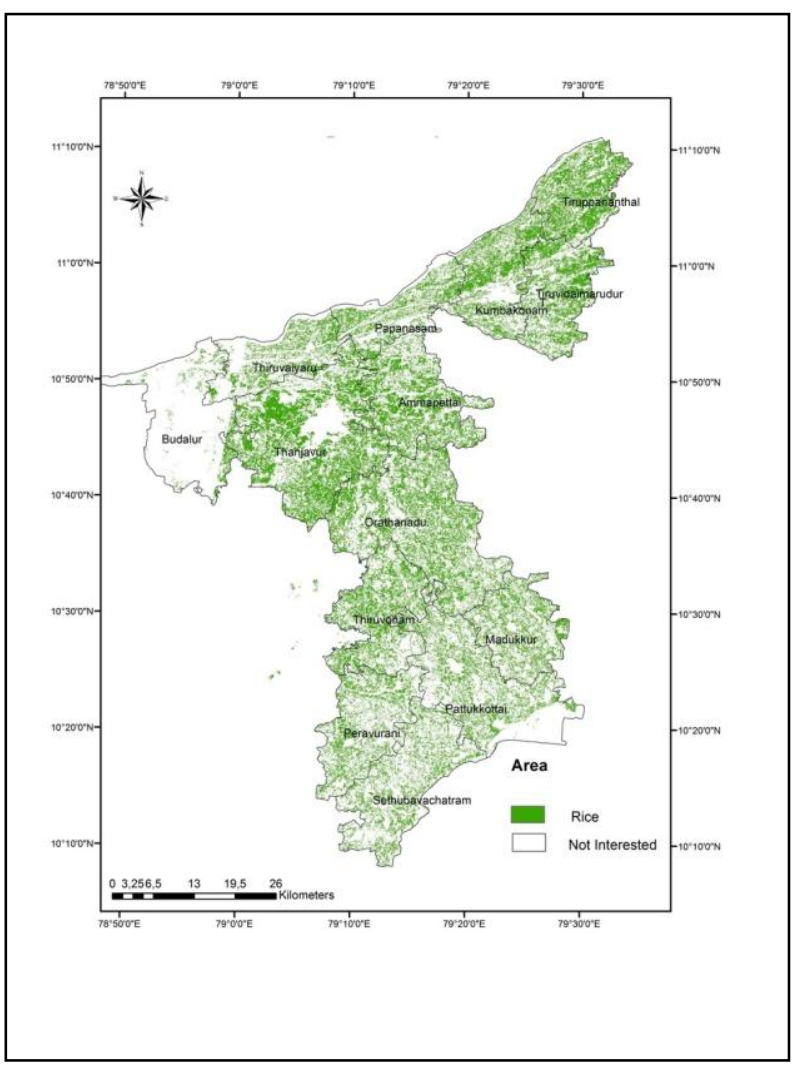

Fig.5 Rice area concentration

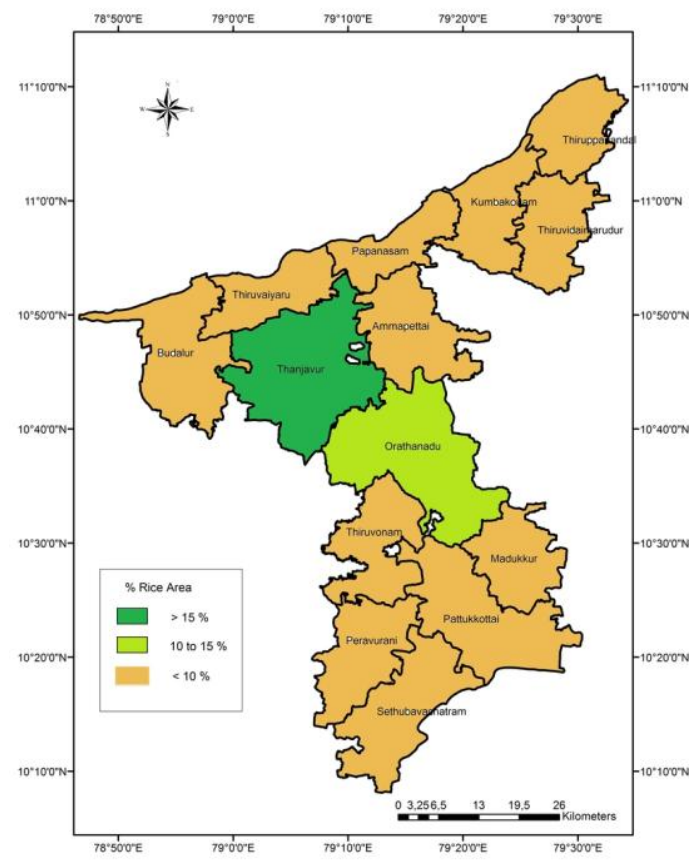


Fig.6 Rice area validation points for rice and non-rice classes across Thanjavur

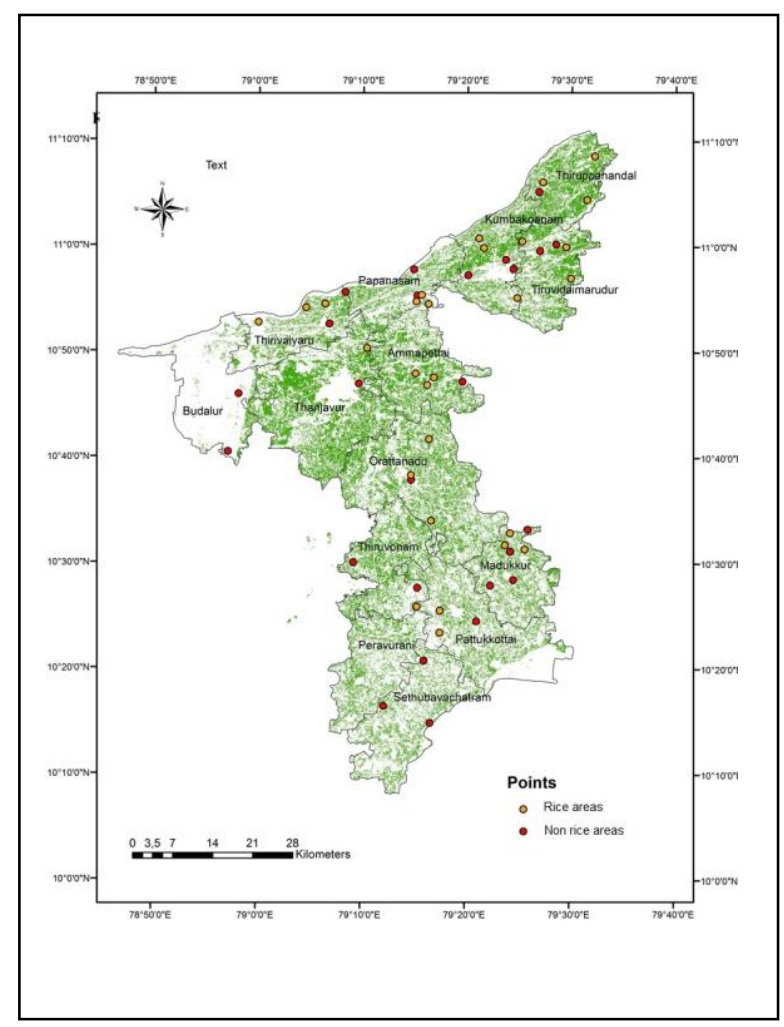

The predicted area is approximately $10-15 \%$ less compared to the last 10 years average rice acreage of the district. This may be due to the reduced availability of Cauvery water and rainfall during the crop growing season. The area of high, and low level concentrations of rice coverage is well represented in the classification. High concentration is observed in Thanjavur and Orathanadu blocks, while low level concentration is found in Peravurani and Sethubavachatram blocks. This is conforming to the study conducted by Punithavathi et al., (2014).

In conclusion, in this study a total of 3 datasets from Landsat 8 OLI were classified using unsupervised-isocluster classification to delineate the rice cultivation area of the test site and for accuracy assessment. With this method a classification accuracy of 87 per cent could be achieved. In Thanjavur district, the Samba rice season coincides with the North- East monsoon season and there is high probability of cloud interference for optical images. Hence there is a need of delineating rice areas with the minimum number of available cloud free temporal images. The idea here is to establish that mono temporal optical datasets obtained from Landsat 8 OLI has good overall accuracy for land cover classification, especially in delineating rice area during the reproductive phase of Samba rice when the possibility of retrieving cloud free optical satellite images are high. Understanding the area under rice approximately one to two months prior to harvesting would be critical in ensuring food security.

\section{References}

Chen, L. 2007. Uncertainties in rice yield estimation using remote sensing data. Ph. D. Thesis, Zhejiang University, Hangzhou Shi, Zhejiang Sheng, China.

Dadhwal, V.K. and Ray, S.S. 2000. Crop assessment using remote sensing-Part II: 
Crop condition and yield assessment. Ind. J. Agric. Econ., 55: 55-67.

FAO. 2016. Rice Market Monitor, 19(1): 37.

Genc, L., Inalpulat, M., Kizil, U. and Aksu. S. 2014. Determination of paddy rice field using Landsat 8 images. Int. Conference on Biol. Civil and Environ. Engi., (BCEE2014) March 17-18, 2014 Dubai (UAE).

Goswami, S.B., Saxena, A. and Bairagi, G.D. 2012. Remote Sensing and GIS based wheat crop acreage estimation of Indore district, M.P. Int. J. Emerg. Technol. Adv. Engi., 2(3).

Huke, R.E. and Huke, E.H. 1997. Rice area by type of culture: South, Southeast, and East Asia. A revised and updated data base. International Rice Research Institute, Los Banos, Laguna, Philippines.

Karydas, C.G., Toukiloglou, P., Minakou, C. and Gitas, I.Z. 2015. Development of a rulebased algorithm for rice cultivation mapping using Landsat 8 time series. Proc. of SPIE - The International Society for Optical Engineering, Vol. 9535.

Khush, G.S. 2005. What it will take to feed 5.0 billion rice consumers in 2030. Plant Mol. Biol., 59:1-6.

Koppe, W., Gnyp, M. L., Hütt, C., Yao, Y., Miao, Y., Chen X. and Bareth, G. 2013. Rice monitoring with multi-temporal and dualpolarimetric Terra SAR-X data. Int. J. Appl. Earth Observation and Geoinformation, 2: 568- 576.

Mosleh, M.K., Hassan, Q.K. and Chowdhury, E.H. 2015. Application of remote sensors in mapping rice area and forecasting its production: A Review. Sensors, 15: 769791

Mostafa, K.K.M. 2015. Use of GIS and Remote Sensing in Mapping Rice Areas and Forecasting Its Production at Large
Geographical Extent, Ph.D. Thesis, University of Calgary, Albaerta, Canada

Okamoto, K. and Kawashima, H. 1999. Estimating of rice- planted area in the tropical zone using a combination of optical and microwave satellite sensor data. Int. J. Remote Sensing, 20(5): 1045-1048.

Punithavathi, J., Tamilenthi, S. and Baskaran, R. 2012. Agricultural concentration and crop wise changes in Thanjavur district, Tamilnadu using geographical information system. Int. Multidisciplinary Res. J., 2(7): 44-48.

Shao, Y., Fan, X., Liu, H., Xiao. J., Ross, S., Brisco, B., Brown, R., and Staples, G. 2001. Rice monitoring and production estimation using multi temporal RADARSAT. Remote Sensing of Environ., 76: $310-325$

Tennakoon, S.B., Murty, V.V.N., Elumnoh, A. 1992. Estimation of cropped area and grain yield of rice using remote sensing. Int. J. Remote Sens., 13: 427-439.

Vaithilingam, R. 2015. Policy Note- Department of Agriculture, Government of Tamil Nadu.

Yang, S., Shen, S., Li, B., Le-Toan, T. and He, W. 2008. Rice mapping and monitoring using ENVISAT ASAR data. IEEE Geosci. Remote Sens. Lett., 5: 108-112.

Yang, X.H. 2007. Study on the remote sensing information extraction of rice based on neural network and support vector machine. $\mathrm{Ph}$. D. Thesis, Zhejiang University, Hangzhou Shi, Zhejiang Sheng, China.

Yedage, A.S., Gavali, R.S. and Survanshi, A. 2013. Assessment of pomegranate orchard using remote sensing and GIS techniques for the Solapur, Maharashtra. Indian Streams Res. J., 3(3).

\section{How to cite this article:}

Ajith, K., V. Geethalakshmi, K.P. Ragunath, S. Pazhanivelan and Panneerselvam, S. 2017. Rice Acreage Estimation in Thanjavur, Tamil Nadu Using Lands at 8 OLIIMAGES and GIS Techniques. Int.J.Curr.Microbiol.App.Sci. 6(7): 2327-2335. doi: https://doi.org/10.20546/ijcmas.2017.607.275 